\title{
Corrosão em tubulações de aço carbono pertencentes ao sistema STU-85 da Base Operacional Geólogo Pedro de Moura (BOGPM) - PETROBRAS / URUCU-AM: estudo de caso
}

\section{Corrosion in carbon steel pipes belonging to the STU-85 system of the Operational Base Geologist Pedro de Moura (BOGPM) - PETROBRAS / URUCU-AM: case study}

Radnay Stepham de Assis Abreu ${ }^{1}$, Rodrigo Tavares de Oliveira², Rodrigo Freitas Guimarães ${ }^{3}$, Marcelo Monteiro Valente Parente ${ }^{4}$, Francisco Nélio Costa Freitas ${ }^{5}$,

\footnotetext{
${ }^{1}$ Mestrado Acadêmico em Energias Renováveis, IFCE, CEP: 61939140, Maracanaú, Ceará, Brasil.

${ }^{1}$ Base de Operações Geólogo Pedro de Moura, BOGPM, Coari, Amazonas, Brasil.

${ }^{2}$ Laboratório de Inspeção e Análise de Falhas, LIAF, Instituto Federal de Educação, Ciência e Tecnologia do Ceará, IFCE, CEP: 61.939-140, Maracanaú, Ceará, Brasil.

${ }^{3,4}$ IFCE, Instituto Federal de Educação, Ciência e Tecnologia do Ceará, CEP: 61600000, Caucaia, Ceará, Brasil.

3,4 e 5 Instituto Federal de Educação, Ciência e Tecnologia do Ceará, IFCE, CEP: 61939140, Maracanaú, Ceará, Brasil. e-mail: radsteel2@gmail.com, radnaystephan@petrobras.com.br, rodrigotavares.industria@gmail.com, marceloparente2@gmail.com rodrigofg18@gmail.com,fneliocf@gmail.com
}

\section{RESUMO}

A Base de Operações Geólogo Pedro de Moura (BOGPM) é hoje referência mundial de convivência harmoniosa entre a atividade de exploração e produção de petróleo e gás e o meio ambiente. Localizada no estado do Amazonas, mais especificamente no município de Coari, produz petróleo de alta qualidade (49 API), o mais leve dentre os processados nas refinarias do Brasil. Esta unidade vem apresentando alto nível de corrosão no Sistema de Tubulações (STU-85) responsável pelo transporte de águas produzidas oriundas dos separadores horizontais trifásicos (SG). Sabe-se que a composição das águas produzidas depende fortemente do campo produtor. Este trabalho tem como objetivo apresentar um estudo de caso que foi observado no processo de inspeção e manutenção periódica, visando correlacionar os fatores responsáveis pela corrosão que foram observados pela equipe de manutenção. Foi verificada a intrínseca relação da morfologia de corrosão no material estrutural da tubulação supracitada com os componentes presentes nas análises das águas produzidas. A morfologia da corrosão se mostrou prioritariamente de forma localizada nas regiões de soldas e curvas. Nos trechos retos da tubulação, a corrosão se apresentou de forma alveolar, ou por descolamento de placas localizado na geratriz inferior interna. A análise da água produzida apresentou altos teores de sais à base de cloreto, componentes à base de enxofre e metais pesados. Conforme a literatura, tais componentes favorecem o processo corrosivo.

Palavras-chave: BOPGM, corrosão, águas produzidas, tubulações, morfologia da corrosão.

\begin{abstract}
The Base de Operações Geólogo Pedro de Moura (BOGPM) is today a world reference of harmonious coexistence between the activity of exploration and production of oil and gas and the environment. Located in the state of Amazonas, more specifically in the municipality of Coari, it produces high quality oil (49 ${ }^{\circ}$ API), the lightest among the processed in the Brazilian refineries. This unit has been showing a high level of corrosion in the Piping System (STU-85) responsible for the transportation of produced waters from three-phase horizontal separators (SG). It is known that the composition of the produced waters depends strongly on the oil field. This work aims to present a case study that was observed in the process of inspection and periodic maintenance, aiming to correlate the factors responsible for corrosion that were observed by the maintenance
\end{abstract}


team. It was verified the intrinsic relationship of the corrosion morphology in the structural material of the aforementioned pipeline with the components present in the analysis of the produced waters. The corrosion morphology was mainly localized and shown in the regions of welds and curves. In the straight sections of the pipe, the corrosion was alveolar and located in the inferior internal generatrix. The analysis of the produced water showed high levels of chloride-based salts, sulfur-based components and heavy metals. According to the literature, such components favor the corrosive process.

Keywords: BOPGM, corrosion, produced waters, pipes, corrosion morphology.

\section{INTRODUÇÃO}

Descoberta em 1986, a Base Operacional Geólogo Pedro de Moura (BOGPM), comumente denominada de Província Petrolífera de Urucu, situa-se na bacia do Rio Solimões, região norte do Brasil, mais especificamente no município de Coari, a $650 \mathrm{~km}$ da capital do Amazonas, Manaus. Trata-se da maior reserva terrestre de gás natural nacional.

De lá, retira-se diariamente, em média, 40 mil barris de petróleo de ótima qualidade e cerca de 13 milhões de metros cúbicos de gás natural. Urucu responde pela produção de aproximadamente 1.200 toneladas de GLP (gás de cozinha) por dia, equivalente a 112 mil botijões de gás de cozinha, volume capaz de abastecer os estados da região norte e parte do nordeste.

Atualmente, a Base Operacional Geólogo Pedro de Moura (BOGPM) conta com uma malha de dutos que possibilitam o escoamento da produção. Desde 2009, o gasoduto Urucu / Coari / Manaus opera interligando a província petrolífera a Manaus, capital do Amazonas, totalizando 663 quilômetros de extensão. O gasoduto tem capacidade de transportar até 5,5 milhões de metros cúbicos por dia de gás natural.

Essa estrutura atual é bem diferente do que havia no início da operação de Urucu. No início, levava-se mais de uma semana para escoar a produção por balsas de pequeno porte pelo rio Urucu, até a cidade de Coari, às margens do rio Solimões e de lá, em balsas maiores, até a Refinaria Isaac Sabbá - Reman.

A Base Operacional Geólogo Pedro de Moura (BOGPM), nome dado em homenagem ao geólogo brasileiro Pedro de Moura, pioneiro da exploração e do mapeamento geológico para carvão e petróleo no Amazonas, possui 7 campos produtores terrestres: Arara Azul; Araracanga; Carapanaúba; Cupiúba; Leste do Urucu (LUC); Rio Urucu (RUC) e Sudoeste Urucu (SUC) [1].

Para processar o petróleo e seus derivados, dispõe de unidades equipadas de: Sistemas de Tratamento e Separação de Petróleo; Sistemas de Armazenamento e Distribuição; Sistemas de Compressão de Gás; 4 Unidades de Processamento de Gás Natural - UPGN; Estação de Tratamento de Efluentes (ETE); Estação de Tratamento de Água (ETA) e Sistemas de Segurança das Unidades.

Água produzida na indústria do petróleo é uma designação genérica para as águas carreadas por óleo ou gás durante a prospecção do petróleo, seja ela proveniente da formação geológica (água de formação) ou decorrente de água de injeção ou ainda da mistura de ambas [2].

Ao se perfurar um poço de petróleo, o mesmo é surgente, ou seja, possui pressão suficiente para expelir a mistura de gás, petróleo e água contidos na jazida. Este processo ocorre em consequência à alta pressão interna dos poços, devido à presença dos gases associados. Com o passar dos anos, a pressão interna diminui, e a prospecção do mesmo necessita de elevação artificial utilizando gás natural (gás lift) ou injeção de água.

A água produzida obtida durante a produção de petróleo e gás, que saem dos separadores horizontais trifásicos (SG) pode ser tratada para remover o óleo disperso, a matéria orgânica, as partículas em suspensão, gases, dióxido de carbono, sulfeto de hidrogênio, sais dissolvidos e contaminantes tóxicos. Após determinado tratamento, pode ser usada para recuperação secundária de poços (injeção), descarregada para cursos d'água, aplicada nas operações de petróleo e gás, empregada em sistemas de irrigação e até utilizada para consumo animal e humano [3].

A quantidade de água produzida associada varia muito durante a vida produtiva dos poços, podendo alcançar valores da ordem de 50 a $100 \%$ em volume final da vida produtiva destes [4].

A composição da água produzida é altamente variável e depende do campo produtor. Consiste de mistura aquosa, contendo principalmente, constituintes orgânicos e inorgânicos. Produtos de corrosão, bactérias e grãos de rochas de formação podem também estar presentes juntamente com o óleo e gases dissolvidos [5].

THOMAS [6] relata que os teores de sais dissolvidos são extremamente variáveis, sendo em média cerca de 3 a 4 vezes superiores aos normalmente existentes na água do mar (33.500 mg/l). Outro aspecto 
comentado pelo autor é o aumento da salinidade com a profundidade do poço. Segundo FERNANDES JUNIOR [7], a concentração de $\mathrm{NaCl}$ pode chegar a $300.000 \mathrm{mg} / \mathrm{L}$ na água produzida.

Segundo AHMADUM et al. [3], a salinidade é atribuída, em maior parte, pela dissolução do sódio e do cloreto, e em menor proporção, a cátions cálcio, magnésio e potássio.

Elementos como: chumbo, bário, mercúrio, manganês, cobre, zinco e cádmio se apresentam em concentrações significativas nas águas produzidas, a depender da idade da formação geológica a partir da qual é produzido o óleo e o gás natural [8].

Gases dissolvidos como $\mathrm{CO}_{2}, \mathrm{H}_{2} \mathrm{~S}$ e sólidos em suspensão são constituintes, em modo geral, de águas produzidas [5].

GABARDO [9] relata que a água produzida pode ainda apresentar concentração de radionuclídeos, normalmente associados às ocorrências naturais de materiais radioativos (rádio-226 e rádio-228).

Devido a todas essas características, as águas produzidas são muito corrosivas aos materiais metálicos, principalmente de tubulações, constituindo uma preocupação constante das empresas e estudiosos do assunto em todo o mundo.

Os polímeros, as bactérias redutoras de sulfato (SBR), o oxigênio dissolvido (DO), o sulfeto de hidrogênio $\left(\mathrm{H}_{2} \mathrm{~S}\right)$ e o íon cloreto na água produzida podem causar falha por corrosão na tubulação, o que resulta em grande risco [10].

A corrosão provocada pelo processamento do petróleo começou a receber a devida atenção no final dos anos 40 e início dos anos 50, devido à necessidade de refino dos petróleos com teor mais elevado de componentes ácidos o que resultou no aumento das perdas pelos processos corrosivos [11].

CUI, Z. et al. [12] investigaram a corrosão de três linhas de água produzida saturada $\mathrm{com}^{\mathrm{CO}}$, em condições estáticas simuladas, utilizando o método de perda de massa e exame visual. A superfície corroída foi investigada por microscopia eletrônica de varredura, complementada com análise de difratometria de raios $\mathrm{X}$ e espectrometria de massa. Os resultados mostraram que as taxas de corrosão reduziram-se significativamente com o aumento da temperatura de exposição. A superfície corroída constituiu-se de uma solução sólida de carbonatos de cálcio $\left(\mathrm{CaCO}_{3}\right)$ e de ferro $\left(\mathrm{FeCO}_{3}\right)$ associada com o mineral de óxido de ferro goethita $(\alpha-\mathrm{FeOOH})$. Os autores concluíram que a solução sólida de carbonatos, formada em temperaturas mais baixas, foi mais estável do que aquela formada em temperaturas elevadas, entre $80^{\circ} \mathrm{C}$ e $90^{\circ} \mathrm{C}$, onde nestas temperaturas os carbonatos de cálcio $\left(\mathrm{CaCO}_{3}\right)$ e de ferro $\left(\mathrm{FeCO}_{3}\right)$ decompunham-se em goethita $(\alpha-\mathrm{FeOOH})$.

XIANG Y. et al. [13] pesquisaram o efeito combinado de $\mathrm{O}_{2}$ e $\mathrm{SO}_{2}$ em tubulações de API 5L X70. Os autores utilizaram o método de perda de massa para determinar o efeito do tempo de exposição nas taxas de corrosão desse aço. A morfologia da superfície corroída foi examinada por microscopia eletrônica de varredura e os produtos de corrosão formados, foram analisados por difratometria de raios X. Os resultados mostraram que o tempo de exposição tem um grande impacto nas taxas de corrosão quando oxigênio está presente, comparativamente à condição isenta de oxigênio.

Outro modelo para prever a taxa de corrosão do aço carbono por água produzida contendo sulfatos, cloretos e sulfeto de hidrogênio foi proposto por SMITH, P. et al. [14], cujo formularam águas produzidas sintéticas para simular o efeito corrosivo de diferentes teores das espécies químicas acima, em amostras de aço carbono extraídas de tubulações de água produzida submarinas. Foi utilizado o método de polarização em uma célula potenciométrica com três eletrodos. Os resultados previstos pelo modelo desenvolvido mostraram uma boa concordância com taxas de corrosão experimentais obtidas no campo em condições similares.

O interesse pelo presente estudo veio de constatações de inspeções e manutenções periódicas no Sistema de Tubulações condutoras de águas produzidas (STU-85) na citada unidade, com a finalidade de correlacionar a morfologia da corrosão aos componentes presentes na análise da água produzida.

\section{MATERIAIS E MÉTODOS}

Esse trabalho foi realizado através da coletânea de dados e informações obtidos através dos arquivos físicos das equipes de manutenção e inspeção da gerência da Unidade Operacional da Amazônia / Engenharia de Produção e Suporte Operacional / Engenharia de Manutenção e Inspeção - UO-AM/ENGPO/EMI durante as atividades diárias realizadas na unidade.

A amostra da água produzida utilizada para o presente estudo foi coletada e armazenada em 2 bombonas de plástico com capacidade de 50L, após pré-tratamento por separador água e óleo (SAO) existente na 
Estação de Tratamento de Efluentes - ETE da BOGPM em 2015, e enviada para análise ao Centro de Pesquisa da Petrobras (CENPES) no mesmo ano, uma vez que no laboratório situado na unidade de Urucu são feitas somente as análises de Salinidade e TOG (Teor de Óleos e Graxas).

Para a análise e obtenção da composição química da água produzida, o Centro de Pesquisa da Petrobras (CENPES) seguiu as diretrizes ABNT NBR 13810 e ASTM D4691.

A água produzida escoa pela tubulação da unidade STU-85 com uma pressão média de $3 \mathrm{kgf} / \mathrm{cm}^{2}$ a uma vazão de $25 \mathrm{~m}^{3} / \mathrm{h}$ aproximadamente. A velocidade de escoamento pode variar de $0,86 \mathrm{~m} / \mathrm{s}$ na secção de 4", podendo chegar a $3,47 \mathrm{~m} / \mathrm{s}$ na região de estrangulamento de 2 ".

Sistema de Tubulações da unidade STU-85 responsável pelo transporte de águas produzidas são confeccionados em aço carbono API 5L GR. B sem costura. Esse tipo de aço é especificamente utilizado em sistemas de oleodutos, gasodutos e outros fins. A tubulação da unidade apresenta diâmetro de 4", "série 40" (schedule 40), com espessura de parede 0,237" e diâmetro nominal 4,5", podendo ter regiões de estrangulamento onde o diâmetro pode chegar a 2", "série 40" (schedule 40, ), com espessura de parede 0,144" e diâmetro nominal 2,37”. Sua composição base está especificada na Tabela 1 [15]

Tabela 1: Composição química do aço API 5L Gr. B em percentual (\%).

\begin{tabular}{|c|c|c|c|c|c|}
\hline & $\mathrm{C}$ & $\mathrm{Si}$ & $\mathrm{Mn}$ & $\mathrm{P}$ & $\mathrm{S}$ \\
\hline API 5L GR. B & $\leq 0,28$ & - & $\leq 1,20$ & $\leq 0,03$ & $\leq 0,03$ \\
\hline
\end{tabular}

Os registros e relatórios correspondentes às Figuras 1 a), b) e c), da Figura 2 a) e b) e Figura 3 c) foram cedidos pela gerência UO-AM/ENGPO/EMI e a Figura 3 a) e b) foram coletadas de parte do Sistema de Tubulações condutoras de água produzida (STU-85) por um dos autores do estudo de caso.

Os dados das Tabelas 2 e 3 foram cedidos pela gerência UO-AM/ENGPO/EMI.

A inspeção é realizada pela própria equipe de operação da unidade STU-85 que ocorre diariamente nos turnos de serviço. Na identificação de vazamentos, as equipes de inspeção e manutenção são acionadas e as mesmas realizam a "manutenção paliativa", conforme é abordado na discussão. As trocas permanentes das seções tubulares ocorrem de acordo com o tipo trecho. Trechos retos, normalmente, são trocados em intervalos de três em três anos, em média. Trechos com derivações, como por exemplo, curvas e estrangulamentos, são trocados em intervalos menores entre cinco a sete meses devido ao alto nível de degradação.

Os ensaios por líquido penetrante (LP) foram todos realizados seguindo as diretrizes da norma ABNT NBR 1640/2016.

\section{RESULTADOS}

$\mathrm{Na}$ Tabela 2 constam os resultados da análise química e físico-química da água produzida solicitada pela Unidade Urucu/AM ao Centro de Pesquisa da Petrobras (CENPES) em 2015.

Tabela 2: Composição química e caracterização físico-química da água produzida de Urucu realizada pelo CENPES em 2015.

\begin{tabular}{c|c}
\hline CONSTITUINTES & SISTEMA DE PRODUÇÃO DE URUCU (mg/L) \\
\hline SÓDIO & $56.000,00$ \\
\hline POTÁSSIO & $1.290,00$ \\
\hline MAGNÉSIO & $1.660,00$ \\
\hline CÁLCIO & $19.870,00$ \\
\hline BÁRIO & 22,00 \\
\hline ESTRÔNCIO & $\mathbf{8 4 0 , 0 0}$ \\
\hline FERRO TOTAL & 46,00 \\
\hline
\end{tabular}




\begin{tabular}{|c|c|}
\hline LíTIO & 27,00 \\
\hline BORO & 70,00 \\
\hline SILÍCIO & 5,00 \\
\hline CLORETO & $134.540,00$ \\
\hline BROMETO & 644,00 \\
\hline SULFATO & 350,00 \\
\hline BICARBONATO & 101,00 \\
\hline ACETATO & 116,00 \\
\hline FORMIATO & $<5,0$ \\
\hline PROPIONATO & $<5,0$ \\
\hline SALINIDADE TOTAL em mg/L NaCI & $222.000,00$ \\
\hline $\mathrm{PH} \mathrm{A} 21^{\circ} \mathrm{C}$ & 5 \\
\hline DENSIDADE A $25^{\circ} \mathrm{C}, \mathrm{g} / \mathrm{cm}^{3}$ & 1,1505 \\
\hline BALANÇO IÔNICO, \% & 2,3 \\
\hline
\end{tabular}

A Figura 1 contém imagens de um flange fabricado em aço carbono unido através de solda por eletrodo revestido a uma redução de 4" para 2" de mesmo material. A peça foi submetida ao ensaio nãodestrutivo (END) por líquido penetrante (LP). Posteriormente ao ensaio realizado, a mesma foi seccionada transversalmente na região onde foi observado o vazamento de água produzida para visualização da corrosão na geratriz inferior interna da peça.

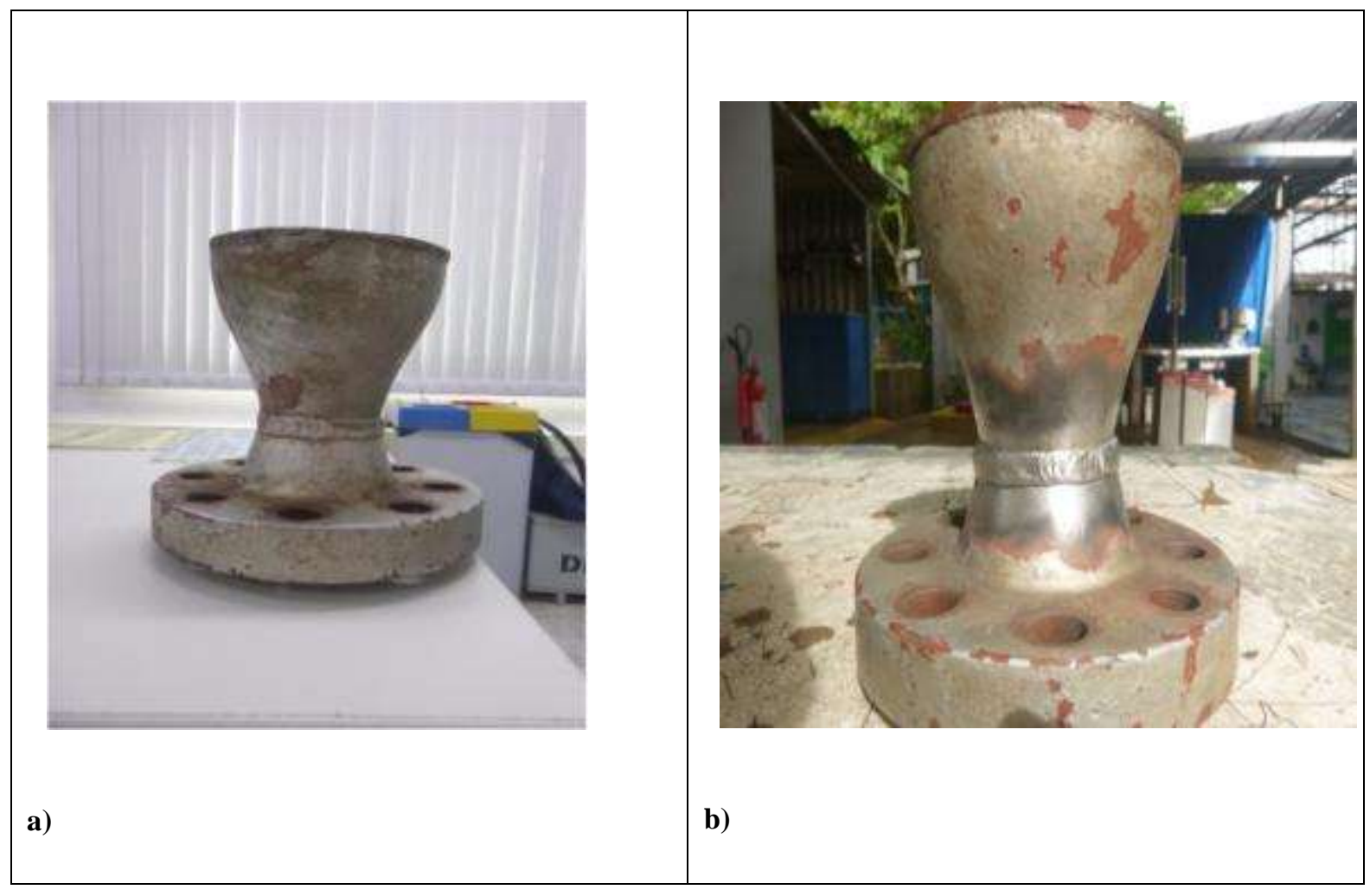




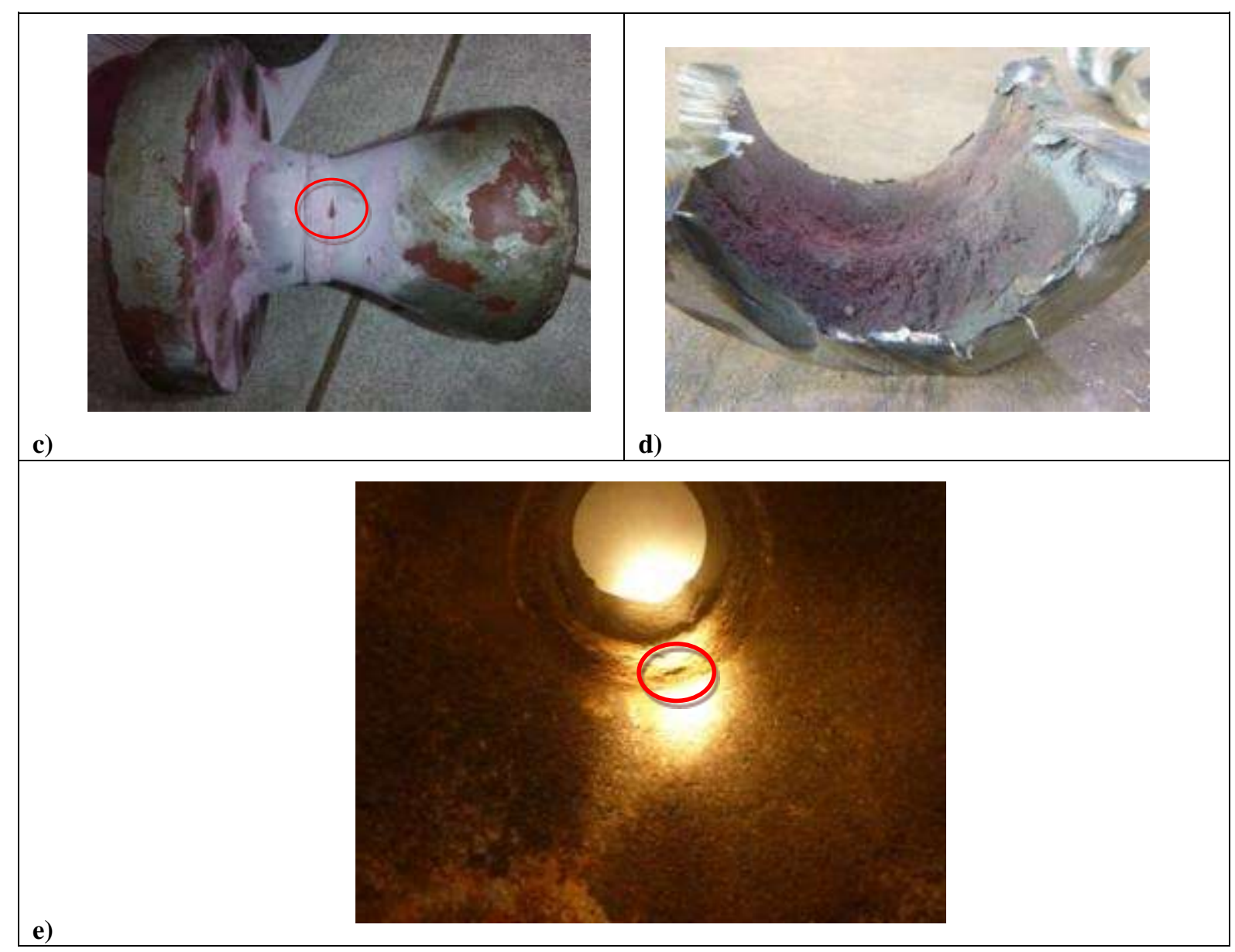

Figura 1: a) Imagem do flange e redução de 4" para 2" antes do tratamento para ensaio não-destrutivo (END) por líquido penetrante (LP). b) Imagem do flange e redução de 4" para 2" após tratamento para ensaio não-destrutivo (END) por líquido penetrante (LP). c) Imagem do flange e redução de 4" para 2" após a realização do ensaio não-destrutivo (END) por líquido penetrante (LP), detalhando a existência de trinca. d) Imagem do corte transversal da secção unida por solda por eletrodo revestido. e) Imagem da geratriz inferior interna do flange, próxima do contorno de solda, detalhando a trinca.

A Figura 2 contém as imagens de um trecho reto unido à curva por eletrodo revestido, onde a equipe de manutenção constatou vazamento. A equipe de inspeção solicitou a retirada da tubulação para estudo de corrosão mais aprofundado, verificando a presença de um furo na geratriz inferior interna da curva. $\mathrm{Na}$ Figura 2 a), observa-se ainda a instalação de uma abraçadeira, de mesmo diâmetro da tubulação, utilizada para contenção de vazamentos. Tal acessório provisório é utilizado pela equipe de manutenção na impossibilidade de parada da unidade ou manobras operacionais, através de by-pass, para a remoção e troca da tubulação. 


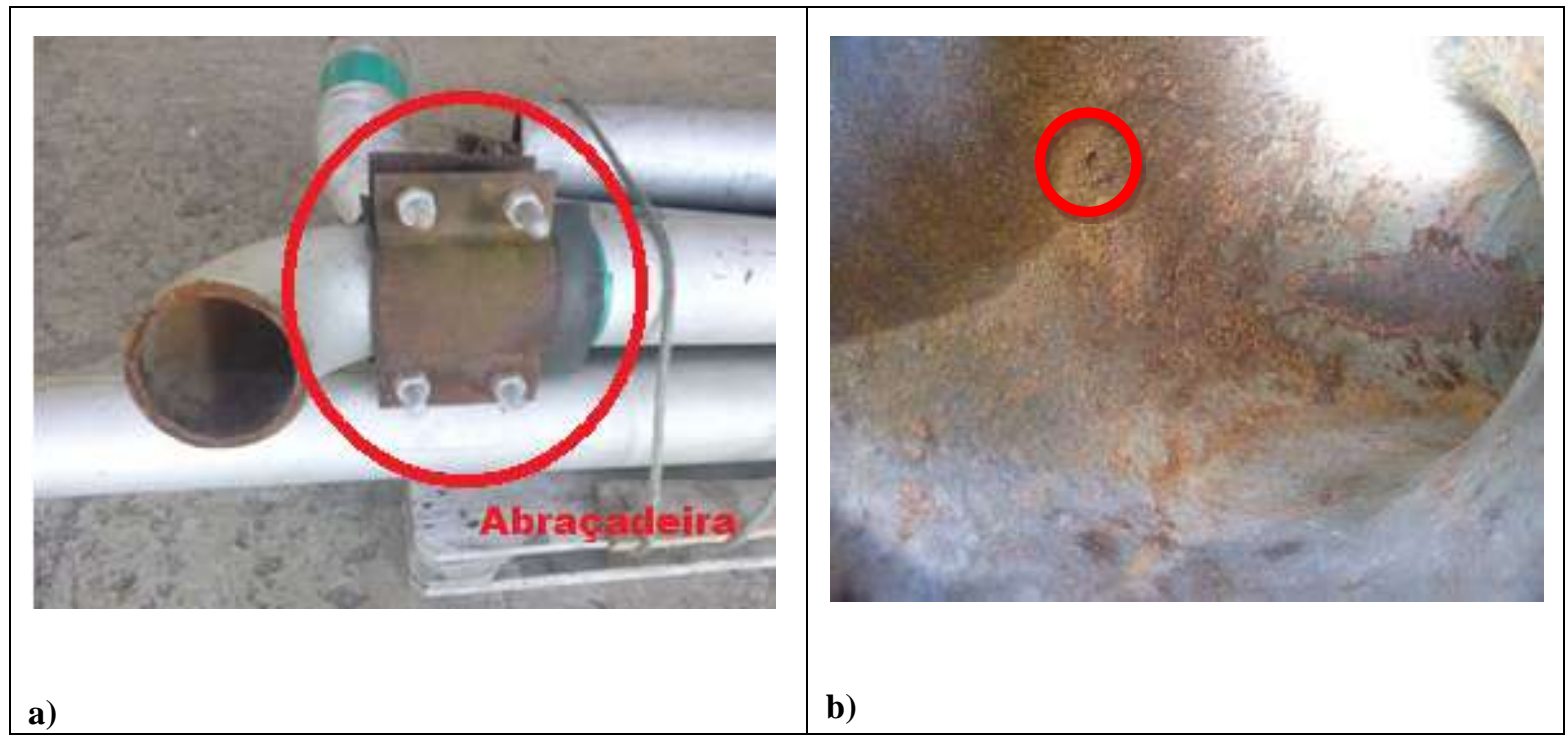

Figura 2: a) Imagem externa do trecho reto unido à curva através de solda por eletrodo revestido. b) Imagem detalhada do furo localizado na geratriz inferior interna da curva.

A Figura 3 a) contém as imagens de trechos, especificamente, retos de parte do STU-85 que conduzem água produzida onde a equipe de manutenção constatou diversos vazamentos em pontos aleatórios. Observa-se ainda que no percurso das linhas existem a presença de abraçadeiras, de mesmo diâmetro da tubulação, utilizadas para contenção de vazamentos. A Figura 3 b) consta um trecho específico da tubulação que apresentou diversos vazamentos e estes foram contidos por abraçadeiras. A Figura 3 c) representa uma imagem da geratriz interna no trecho reto da tubulação. 


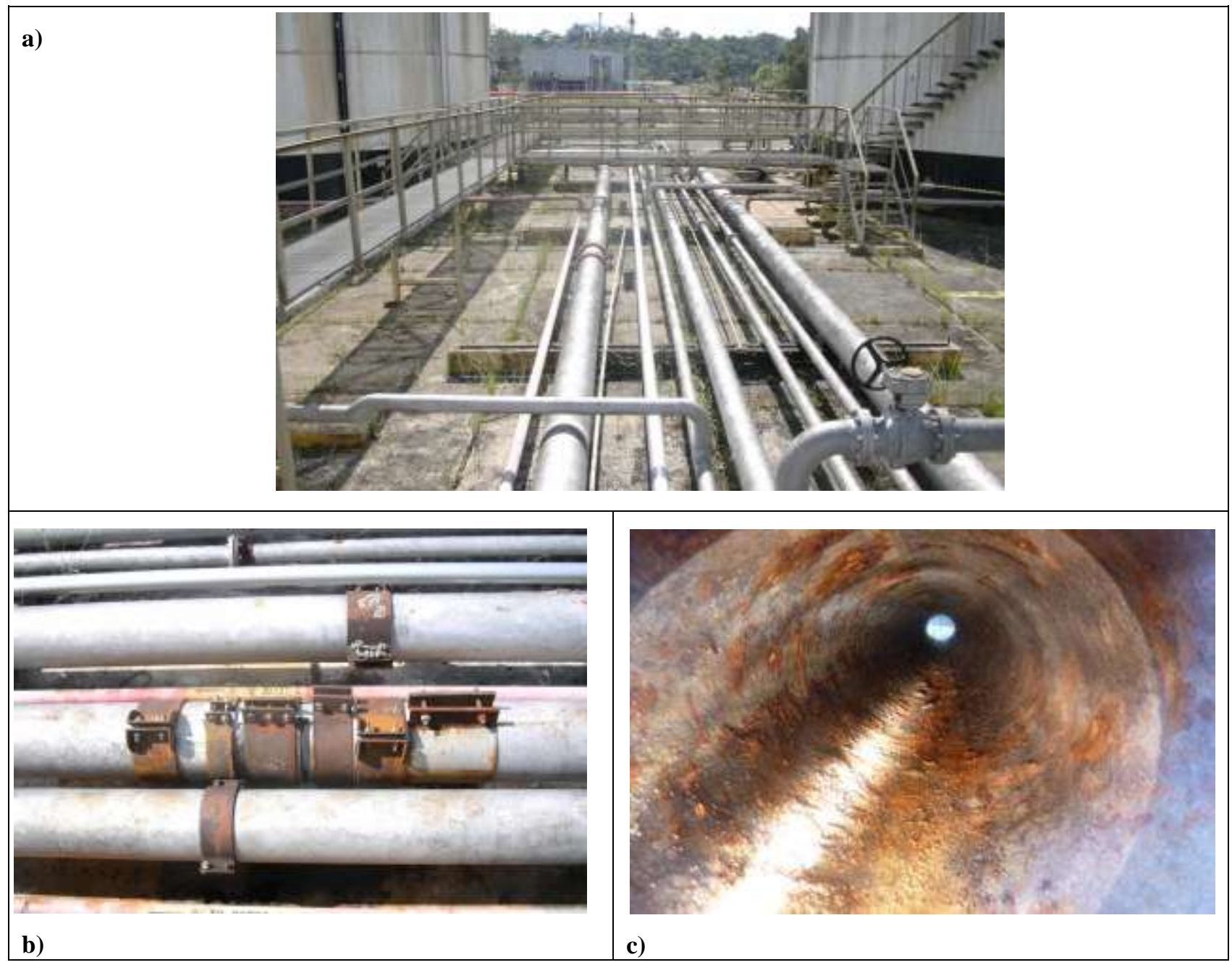

Figura 3: a) Imagem panorâmica das tubulações de parte do sistema de tubulações STU-85 responsável pela condução da água produzida. b) Imagem do trecho específico das tubulações de parte do sistema de tubulações STU-85 responsável pela condução da água produzida. c) Imagem da geratriz interna no trecho reto da tubulação pertencente ao sistema de tubulações STU-85 responsável pela condução da água produzida.

A Tabela 3 apresenta o histórico de ocorrências no sistema de tubulações STU-85 feita pela equipe de inspeção da gerência Unidade Operacional da Amazônia / Engenharia de Suporte Operacional / Engenharia de Manutenção e Inspeção (UO-AM/ENGPO/EMI).

Tabela 3: Histórico resumido das ocorrências de furos em tubulações do sistema de água produzida de Urucu.

\begin{tabular}{c|c|c|c|c}
\hline DATA & $\begin{array}{c}\text { OCORRÊNCIAS NO STU - } \\
85\end{array}$ & $\begin{array}{c}\text { QUANTIDADE DE } \\
\text { LINHAS AFETADAS }\end{array}$ & $\begin{array}{c}\text { CARACTERÍSTICAS DA } \\
\text { CORROSÃO }\end{array}$ & LOCAL \\
\hline $\mathbf{0 2 / 1 1 / 2 0 0 3}$ & 4 FUROS & 1 & ALVEOLAR INTERNA & TRECHO RETO \\
\hline $23 / 11 / 2006$ & $\begin{array}{c}\text { VÁRIOS FUROS (NÃO } \\
\text { QUANTIFICADOS) }\end{array}$ & 1 & ALVEOLAR INTERNA & TRECHO RETO \\
\hline $29 / 11 / 2009$ & $\begin{array}{c}\text { 7 FUROS EM JUNTAS } \\
\text { SOLDADAS }\end{array}$ & 5 & LOCALIZADA & SOLDAS \\
\hline $11 / 07 / 2011$ & $\begin{array}{c}\text { VÁRIOS FUROS (NÃO } \\
\text { QUANTIFICADOS) }\end{array}$ & 1 & LOCALIZADA & $\begin{array}{c}\text { SOLDAS E CUR- } \\
\text { VAS }\end{array}$ \\
\hline
\end{tabular}




\begin{tabular}{c|c|c|c|c}
\cline { 2 - 5 } & $\begin{array}{c}\text { VÁRIOS FUROS (NÃO } \\
\text { QUANTIFICADOS) }\end{array}$ & 12 & LOCALIZADA & $\begin{array}{c}\text { CURVAS E TRE- } \\
\text { CHOS RETOS }\end{array}$ \\
\hline $13 / 07 / 2012$ & $\begin{array}{c}\text { VÁRIOS FUROS (NÃO } \\
\text { QUANTIFICADOS) }\end{array}$ & 2 & LOCALIZADA & SOLDAS \\
\hline $10 / 06 / 2015$ & 1 FURO & 1 & $\begin{array}{c}\text { EROSÃO POR CRISTAIS } \\
\text { DE SAL }\end{array}$ & VÁLVULA \\
\hline
\end{tabular}

\section{DISCUSSÃO}

Conforme os dados apresentados na Tabela 2, verifica-se que a água produzida é bastante rica em sais expresso em NaCl, apresentando, aproximadamente, $222.000 \mathrm{mg} / \mathrm{L}$, estando de acordo com a literatura. Segundo o autor FERNANDES JUNIOR [7] a salinidade total pode chegar a $300.000 \mathrm{mg} / \mathrm{L}$. Somando-se a este resultado, o teor de cloreto proveniente de outros sais é de aproximadamente $135.000 \mathrm{mg} / \mathrm{L}$.

Os cloretos induzem a um alto nível de corrosão por ser um íon de diâmetro bastante pequeno, podendo penetrar na estrutura intergranular metálica. Este tipo de ataque resulta, frequentemente, em corrosão do tipo localizada.

Conforme a literatura, em aços passiváveis, o íon cloreto instabiliza a camada de passivação, destruindo a película protetora. A destruição de um filme passivo resulta na formação de uma área anódica. Portanto, o rompimento da película de proteção passiva sobre a superfície do metal, resulta em várias regiões anódicas e a superfície circundante, atuando como região catódica, resultando na corrosão do tipo localizada por pites (pitting corrosion) [16].

Em aços carbono propriamente dito, ou seja, não passiváveis, ou muito pouco passiváveis, o cloreto, de forma geral, atacará toda a superfície uniformemente. No entanto, se a estrutura metálica apresentar heterogeneidade, causada por impurezas, contornos de grão e superfície áspera, por exemplo, esse ataque poderá ocorrer de forma localizada [17].

Observa-se ainda na Tabela 2 que a água produzida apresenta $\mathrm{pH}$ levemente ácido. Também pode ser visto que a água produzida possui teores consideráveis de bicarbonato. Este por sua vez, em meio ácido, pode induzir a formação de gás carbônico $\left(\mathrm{CO}_{2}\right)$. $\mathrm{O}$ gás carbônico $\left(\mathrm{CO}_{2}\right)$, por conseguinte, pode provocar corrosão severa que dependendo de fatores como temperatura e pressão poderão formar na superfície do aço camadas de carbonato ferroso $\left(\mathrm{FeCO}_{3}\right)$ e, dependendo de suas propriedades, as taxas de corrosão podem variar drasticamente [18]. Conforme já foi exposto, a pressão interna média no processo de escoamento da água produzida pode chegar a $3 \mathrm{kgf} / \mathrm{cm}^{2}$ na unidade STU-85, ou seja, esta pressão é cerda de três vezes a pressão externa, sugerindo que este processo de escoamento pode favorecer a formação de carbonato ferroso $\left(\mathrm{FeCO}_{3}\right)$ na superfície interna da tubulação.

Somando aos fatores supracitados, pode ser visto ainda na Tabela 2 que a água produzida apresenta altos teores de íons, ou seja, ela é extremamente condutora. Esta condição, por sua vez, favorecem o processo corrosivo, ou seja, aumenta a cinética de degradação da estrutura metálica [19].

Na Figura 1, expõe as imagens de um ensaio não-destrutivo (END) por líquido penetrante (LP) realizado em uma peça que sofreu vazamento decorrente de processo corrosivo. O ensaio realizado detectou a existência da propagação de trinca na zona térmica afetada (ZTA). A literatura associa este tipo de corrosão à heterogeneidade existente em torno da região soldada. Geralmente, conforme a literatura, a falha ou rompimento ocorrerá de forma localizada e na zona térmica afetada (ZTA), conforme foi observado. Na imagem da Figura $1 \mathbf{e}$ ), pode-se perceber que a geratriz inferior apresentou redução de espessura devido ao ataque corrosivo. Na zona térmica afetada (ZTA), ocorreu um concentrador de tensão que resultou na propagação de uma trinca, onde esta transfixou toda a espessura da tubulação. Conforme pode ser observado na Figura 1 c) (visualização da trinca na geratriz externa) e Figura e) (visualização da formação da trinca na geratriz interna).

A Velocidade de escoamento, calculada a partir da vazão, aumenta drasticamente para as regiões de estrangulamentos (diâmetros menores de 2"). Nesta região a velocidade do fluido pode chegar a ser quatro vezes superior a velocidade nas secções retas da tubulação com diâmetro de 4". Sabe-se também que que nos trechos com derivações do tipo curvo, ocorre um maior concentrador de choques de material particulados. Isso sugere que, além da corrosão resultante por concentração de tensão nestas regiões, existe também o efeito do desgaste mecânico abrasivo resultante do choque do material particulados contidos no fluido. Este resultado vem ao encontro da literatura. Segundo SABINO [20], as perdas de espessuras internas acontecem 
de maneira mais comum em torno da geratriz inferior, por onde água e sedimentos mais pesados escoam, facilitando a corrosão e abrasão.

Observa-se nas imagens da Figura 2 que a corrosão se apresenta mais acentuada próxima à região em torno da solda. Somando-se a esta observação, a equipe de inspeção observou que o rompimento ocorre, com mais frequência, na junção do trecho reto com a curva. Este resultado pode estar associado à heterogeneidade existente em torno da zona afetada termicamente (ZTA) associada ao efeito da ação erosiva de compostos particulados que possam existir na água produzida e ação do impacto no escoamento do fluido.

Observando especificamente a região da geratriz inferior interna dos trechos retos, na Figura 3 c), visualiza-se uma morfologia de corrosão do tipo alveolar ou por descolamento de placas (produto de corrosão) uniformemente distribuída em toda a extensão tubular. $\mathrm{O}$ aço carbono apresenta tipicamente corrosão de forma generalizada e uniforme. A presença da corrosão alveolar ou por descolamento de placas sugere que a ação erosiva do fluido, devido, principalmente, a sua velocidade de escoamento, remove produtos de corrosão formados na superfície interna da tubulação. A remoção do produto corrosivo interno intensifica ainda mais a degradação na superfície metálica, uma vez, que a superfície fica mais exposta ao meio corrosivo. Desta forma, naturalmente ocorre o aumento da profundidade dos alvéolos e diminuição da espessura interna da tubulação, fragilizando-a.

Conforme já foi explanado anteriormente, a água produzida apresenta em sua composição altos teores de cloreto que favorece fortemente a cinética corrosiva.

A Figura 3 a) contém as imagens de trechos especificamente retos do STU-85 que conduzem água produzida onde a equipe de manutenção constatou diversos vazamentos em pontos aleatórios. Observa-se ainda que no percurso das linhas existe a presença de abraçadeiras, de mesmo diâmetro da tubulação, utilizada para contenção de vazamentos. A Figura 3 b) consta um trecho específico da tubulação que apresentou diversos vazamentos e estes foram contidos por abraçadeiras. A Figura 3 c) representa uma imagem da geratriz interna no trecho reto da tubulação.

A Tabela 3 é um resumo das inspeções realizadas entre 2003 a 2015, pode ser observado na mesma que os trechos mais afetados estão associados aos locais onde existem maiores concentrações de tensão, principalmente, nas regiões em torno da solda. frequência.

No entanto, os trechos retos também apresentam necessidade de reparos, porém, com menos

\section{CONCLUSÃO}

De acordo com a análise química e físico-química realizada, a água produzida se apresenta como extremamente condutora e rica em cloro, favorecendo consideravelmente a cinética do processo corrosivo em tubulações de aço carbono.

A corrosão se apresentou mais intensamente, e com mais frequência, nas regiões onde existe maior concentração de tensões, principalmente, nos trechos derivados do tipo curvos e de estrangulamento.

Os trechos retos exibem uma morfologia de corrosão alveolar ou por descolamento de placas (produto de corrosão) que se apresenta de forma uniforme em toda extensão da tubulação.

O processo erosivo induzido por partículas sólidas e pelo escoamento contribuem sensivelmente na intensificação da corrosão que afeta a tubulação.

\section{AGRADECIMENTOS}

Os autores agradecem às equipes de manutenção e inspeção da gerência UO-AM/ENGPO/EMI pelas concessões, dados, informações e apoio cedidos para a realização deste trabalho, sem esquecer da grande contribuição ao estudo do gerente Marques de Sousa Cavalcante. 


\section{BIBLIOGRAFIA}

[1] AGÊNCIA NACIONAL DE PETRÓLEO, GÁS NATURAL E BIOCOMBUSTÍVEIS - ANP, http://www.anp.gov.br/wwwanp/dados-estatisticos. Acessado em agosto de 2017.

[2] CARVALHO, P. C. A. P. Caracterização de água produzida na indústria de petróleo para fins de descarte e otimização do processo de separação óleo/água, Dissertação de M.Sc., PPGEQ/UFRN, Natal, RN, Brasil, 2011.

[3] AHMADUM, F.R, PENDASTHEH, A., AIBUDLLAH, L. C. A., et al., "Review of technologies for oil and gas produced water treatment”, Journal of Hazardous Materiais, v. 170, n. 2-3, pp. 530-531, Oct. 2009.

[4] SILVA, L. H. N., NICODEMO, L. P. "Gestão de água produzida nas atividades petrolíferas onshore: licenciamento ambiental de sistemas de injeção de água na Bacia Potiguar, Rio Grande do Norte - 2016”, In: VII Congresso Brasileiro de Gestão Ambiental, v. 034, Campina Grande, Paraíba, Brasil, 21 - 24 Novembro 2016.

[5] FONSECA, R. M. R. A importância do aproveitamento da água resultante da produção de petróleo Monografia de Esp., COPES/UFS, Aracajú, SE, Brasil, 1999.

[6] THOMAS, J. E., Fundamentos da Engenharia de Petróleo, 2 ed., Rio de Janeiro, Editora Interciência Ltda, 2001.

[7] FERNADES JUNIOR, W. E. Projeto e operação em escala semi-industrial de um equipamento para o tratamento de águas produzidas na indústria do petróleo utilizando nova tecnologia: Misturador - Decantador à inversão de fases (MDIF). Tese de D.Sc., PPGEQ/UFRN, Natal, RN, Brasil, 2006.

[8] BRAGA, R. M. Uso de argilominerais e diatomita como adsorventes de fenóis em águas produzidas na indústria do petróleo. Dissertação de M.Sc., PPGCEP/UFRN, Natal, RN, Brasil, 2004.

[9] GABARDO, I. T. Caracterização química e toxicológica da água produzida descartada em plataformas de óleo e gás na costa brasileira e seu comportamento dispersivo no mar. Tese de D.Sc., PPGEQ/UFRN, Natal, RN, Brasil, 2007.

[10] LIU, Y., ZHANG, Y., YUAN, J. "Influence of produced water with high salinity and corrosion inhi bitors on the corrosion of water injection pipe in Tuha oil field", Engineering Failure Analysis, v.45, pp. 225233, Oct. 2014.

[11] CARVALHO, L. J. Estudo do comportamento de revestimentos à base de Nióbio aplicados por Aspersão Térmica a Chama, na corrosão de aços ao carbono em presença de ácidos naftênicos e sulfetos em altas temperaturas, Tese de D.Sc., COPPE/UFRJ, Rio de Janeiro, RJ, Brasil, 2004.

[12] CUI, Z. D., WU, S. L., ZHU, S. L., et al., "Study on corrosion properties of pipelines in simulated produced water saturated with supercritical CO2”, Applied Surface Science, v. 255, n. 6, pp. 2368-2374, Jan, 2006.

[13] XIANG, Y., WANG, Z., Li, Z, et al., "Effect of Exposure Time on the Corrosion Rates of X70 Steel in Supercritical CO2/SO2/O2/H2O Environments”, Corrosion Science, v. 69, n.3, pp. 251-258. Oct. 2012.

[14] SMITH, P., ROY S., SWAILES D., et al., "A model for the corrosion of steel subjected to synthetic produced water containing sulfate, chloride and hydrogen sulfide", Chemical Engineering Science, v. 66, n. 23, pp. 5775-5790. Dec. 2011.

[15] TELLES, P. C. S. Tubulações Industriais - Materiais, Projeto, Montagem, 10 ed., Rio de Janeiro, Editora Interciência Ltda, 2012.

[16] PELliCCIONE, A. S., MORAES, M. F., GALVÃO, J. L. R., et al., Análises de falhas em equipamentos de processo: mecanismos de danos e casos práticos, 1 ed., Rio de Janeiro, Editora Interciência Ltda, 2012.

[17] TELLES, P. C. S., Materiais para Equipamentos de Processo, 6 ed., Rio de Janeiro, Editora Interciência Ltda, 2003.

[18] LI, T., YANG, Y., GAO, K., et al., "Mechanism of protective film formation during CO2 corrosion", Journal of University of Science and technology Beijin,Mineral, Metallurgy, Material, v. 15, n. 6, pp. 702706, Dec. 2008.

[19] BARD, A. J., FAULKNER, L. R. Electrochemical Methods: Fundamentals and Application., 2 ed., New York, John Wiley \& Sons, 2001.

[20] SABINO, J. M., Avaliação por pig de perfilagem de danos superficiais nos materiais da parede de dutos de petróleo, Dissertação de M.Sc., PPGEM/UFRN, Natal, RN, Brasil, 2009. 


\section{ORCID}

Radnay Stepham de Assis Abreu

https://orcid.org/ 0000-0003-3746-7328

Rodrigo Freitas Guimarães

https://orcid.org/ 0000-0002-5949-2666

Rodrigo Tavares de Oliveira

https://orcid.org/ 0000-0003-1550-6648

Marcelo Monteiro Valente Parente https://orcid.org/ 0000-0003-3497-7891

Francisco Nélio Costa Freitas

https://orcid.org/ 0000-0001-6743-7563 